\title{
Mother's Milk-Induced Hsp70 Expression Preserves Intestinal Epithelial Barrier Function in an Immature Rat Pup Model
}

\author{
JENNIFER L. LIEDEL, YUEE GUO, YUEYUE YU, SHENG-RU SHIOU, SANGZI CHEN, ELAINE O. PETROF, SHIEN HU, \\ MARK W. MUSCH, AND ERIKA C. CLAUD \\ Departments of Pediatrics [J.L.L., Y.G., Y.Y., S.-R.S., S.C., E.C.C.] and Medicine [S.H., M.W.M., E.C.C.], The University of Chicago, \\ Chicago, Illinois 60637; Department of Medicine [E.O.P.], Queen's University, Kingston, Ontario K7L 2V7, Canada
}

\begin{abstract}
Preterm infants face many challenges in transitioning from the in utero to extrauterine environment while still immature. Failure of the preterm gut to successfully mature to accommodate bacteria and food substrate leads to significant morbidity such as neonatal necrotizing enterocolitis. The intestinal epithelial barrier plays a critical role in gut protection. Heat shock protein 70 (Hsp70) is an inducible cytoprotective molecule shown to protect the intestinal epithelium in adult models. To investigate the hypothesis that Hsp70 may be important for early protection of the immature intestine, Hsp70 expression was evaluated in intestine of immature rat pups. Data demonstrate that Hsp70 is induced by exposure to mother's milk. Hsp70 is found in mother's milk, and increased Hsp70 transcription is induced by mother's milk. This Hsp70 colocalizes with the tight junction protein ZO-1. Mother's milk-induced Hsp70 may contribute to maintenance of barrier function in the face of oxidant stress. Further understanding of the means by which mother's milk increases Hsp70 in the ileum will allow potential means of strengthening the intestinal barrier in at-risk preterm infants. (Pediatr Res 69: 395-400, 2011)
\end{abstract}

$\mathrm{T}$ The single layer of enterocytes lining the intestinal epithelium forms a functional barrier between the luminal contents of the gut and the host. This critical barrier is responsible for allowing nutrients and beneficial macromolecules to cross while preventing translocation of bacteria and bacterial products (1). The intestinal barrier comprises a mucin layer covering the intestinal epithelial cells, the epithelial cell plasma membrane, and the apical junctional complex between cells (1). The apical junctional complex consists of a network of tight junction proteins and the adherens junction, both anchored by a perijunctional actomyosin ring (2). The tight junction is a principal determinant of mucosal permeability.

The requirements for the intestinal barrier change over the course of development (3-6). In utero, the gut lumen is bathed in amniotic fluid and has no contact with bacteria or food substrates. Thus, the intestine has high permeability to allow passage of macromolecules critical for development from the amniotic fluid $(6,7)$. After birth, the barrier must appropriately accommodate bacteria and products of digestion. The preterm infant, expecting

Received September 17, 2010; accepted November 16, 2010.

Correspondence: Erika C. Claud, M.D., Department of Pediatrics, Neonatology, The University of Chicago, 5841 S. Maryland Ave MC6060, Chicago, IL 60637; e-mail: eclaud@peds.bsd.uchicago.edu

Supported by NIH grants NIDDK K08 HD049514 [J.L.], HD 59123 [E.C.C.], HD 55237 [E.C.C.], and AT 00404 [E.C.C., E.O.P.] and Digestive Disease Research Core Center DK42086. continuation of the in utero environment, carries much of the immature phenotype designed for in utero life into the extrauterine world. This includes a porous intestinal barrier not prepared for sudden exposure to intestinal bacteria. Thus, the immature gut of preterm infants has increased translocation of intestinal bacteria, predisposing the preterm infant to sepsis and neonatal necrotizing enterocolitis (NEC) (8-10). The immature gut has been shown to have an exaggerated inflammatory response to intestinal bacteria $(9,11-13)$. Permeability across the tight junction can be increased by inflammatory cytokines such as IFN $\gamma$ and $\mathrm{TNF} \alpha$, thus further increasing bacterial translocation and the cycle of injury $(1,14,15)$.

Inducible heat shock protein (Hsp) 70 is a cytoprotective protein shown to have important roles in intestinal protection and regeneration both in vitro and in vivo (16-19). Hsp70 has specifically been shown to maintain barrier function, in part, by stabilizing the tight junctions between intestinal epithelial cells $(20,21)$. This intestinal epithelial protection is associated with restricted bacterial translocation and a reduction in inflammation (22). The role of Hsps in the immature gut has not been previously explored. Only one study has investigated the temporal pattern of Hsp expression. This study in newborn pigs investigated a number of Hsps following weaning (23). We hypothesized that Hsp70 may be important for early protection, before weaning, of the immature intestine in the face of stressors leading to inflammation.

\section{METHODS}

Neonatal rat pups. Animal experiments were approved by the animal care committee at the University of Chicago. All rat pups were allowed to spontaneously deliver and then remain with the mother for rearing (motherfed) or separated from mother for stresses. Stressed pups were housed in a humidified incubator maintained at $37^{\circ} \mathrm{C}$. Formula-fed pups were gavaged every $3 \mathrm{~h}$ with Esbilac puppy formula via an orogastric tube. For $24 \mathrm{~h}$, animals were fed $0.1 \mathrm{~mL}$ every $3 \mathrm{~h}$, which was increased daily by $50 \mu \mathrm{L}$ every $3 \mathrm{~h}$ until killing.

Immunohistochemistry staining. Intestinal segments were removed, opened longitudinally, washed three times in saline, and fixed in formalin. Paraffin-embedded tissues were cut into $4-\mu \mathrm{m}$-thick sections. The sections were deparaffinized at $56^{\circ} \mathrm{C}$, immersed in xylene three times, and hydrated with ethanol (two times with $100 \%$, two times with $95 \%$, and one time with $75 \%$ ethanol) for $5 \mathrm{~min}$. For antigen unmasking, slides were heated in 10-mM sodium citrate buffer $(\mathrm{pH}$ 6.0) for $15 \mathrm{~min}$ before treatment with $0.3 \%$ hydrogen peroxide for $30 \mathrm{~min}$. The specimens were treated with $5 \% \mathrm{BSA}$ in TBST (Tris-buffered saline with $0.05 \% \mathrm{vol} / \mathrm{vol}$ Tween-20) for $30 \mathrm{~min}$ at room

Abbreviations: H\&E, hematoxylin and eosin; Hsp, heat shock protein; NEC, neonatal necrotizing enterocolitis 
temperature followed by overnight incubation with mouse anti-Hsp70 antibody (MAB1663; R\&D Systems, Minneapolis, MN) at $4^{\circ} \mathrm{C}$. After washing, the sections were incubated with polymer-HRP anti-mouse (Dako, Carpinteria, $\mathrm{CA}$ ) for $30 \mathrm{~min}$ at room temperature. Positive staining was visualized with DAB chromogen, and nuclei counterstain was performed with hematoxylin (HHS32; Sigma Chemical Co., St. Louis, MO).

Quantitative measurement of Hsp70 in rat dam milk. Rat milk was collected postmortem from lactating dams on postnatal d 10, using gentle suction. Whole milk was centrifuged $\left(700 \times \mathrm{g}\right.$ for $10 \mathrm{~min}$ at $\left.4^{\circ} \mathrm{C}\right)$ and supernatant Hsp70 measured by ELISA (EKS-700B; Assay Designs, Boulder, $\mathrm{CO})$ as per manufacturer's instructions.

Real-time PCR for Hsp $\boldsymbol{m} \boldsymbol{R N A}$. Total RNA was extracted from ileal tissue by TRIzol (Invitrogen, Carlsbad, CA) according to the manufacturer's instruction. cDNA was synthesized using SuperScript II (Invitrogen) and random hexonucleotide primer. The rat Hsp70 sequences were downloaded from GenBank. The forward and reverse primers were for rat Hsp70 (NM_031971, bases 25-139) and rat GAPDH (NM_017008, bases 154-223). Real-time PCR was performed with an iCycler using iQSYBR Green PCR Supermix (Bio-Rad, Hercules, CA). The two-step quantification cycling protocol was used. The $\mathrm{Ct}$ value is defined as the cycle number at which the fluorescence crosses a fixed threshold above the baseline. As a relative quantitation, fold changes were measured using the $\Delta \Delta \mathrm{Ct}$ method (24)

Ex vivo intestinal loops and assessment of barrier function. Sections of ileum $1-1.5 \mathrm{~cm}$ in length were taken beginning $1 \mathrm{~cm}$ above the ileocecal junction. The segments were flushed with warm PBS to remove stool. The ends were secured with silk ties and the lumen filled with $10 \mathrm{mg} / \mathrm{mL}$ of $10 \mathrm{kD}$ FITC-dextran (Sigma Chemical Co.) with or without freshly prepared $0.1 \mathrm{mM}$ monochloramine $\left(\mathrm{NH}_{2} \mathrm{Cl}\right)$ until moderate distension was achieved $(75 \mu \mathrm{L})$ (20). The loops were placed in the inner well of organ culture dishes (Falcon; Becton Dickinson Labware, Franklin Lakes, NJ) filled with RPMI 1640 medium with $10 \% \mathrm{vol} / \mathrm{vol}$ heat-inactivated fetal bovine serum. These were incubated for $1 \mathrm{~h}$ at $37^{\circ} \mathrm{C}$ in a $5 \% \mathrm{CO}_{2}$ incubator. At 30 and $60 \mathrm{~min}, 100 \mu \mathrm{L}$ of the bathing media was removed for measurement of fluorescence to determine translocation across the loops. Translocated FITC-dextran was quantified by fluorescence and concentration determined by a standard curve of known amounts of FITC-dextran, normalized to intestinal length in millimeters, and expressed as fold change over baseline. The middle section of these loops was removed, placed in $10 \%$ buffered formalin, and embedded for sectioning and immunohistochemistry.

Hsp70 and ZO-1 immunofluorescence staining. Sections were prepared as described for immunohistochemistry staining. The specimens were treated with 5\% BSA in TBST for $30 \mathrm{~min}$ at room temperature followed by overnight incubation with mouse anti-Hsp70 antibody (R\&D Systems) or rabbit antiZO-1 (Invitrogen) at $4^{\circ} \mathrm{C}$. After overnight incubation with primary antibody and washing, sections were incubated with Cy2-anti-mouse and Cy5 antirabbit (Jackson ImmunoResearch, West Grove, PA) overnight at $4^{\circ} \mathrm{C}$. Slides were washed with saline five times, incubated briefly with $4^{\prime}, 6$-diamidino-2phenylindole (DAPI; final concentration $1 \mu \mathrm{g} / \mathrm{mL}$ for $5 \mathrm{~min}$; Molecular Probes, Eugene, OR) to stain nuclei, washed three times in saline, and coverslips mounted using Slow Fade mounting medium (Molecular Probes) and visualized. Confocal microscopy was performed using a Leica SP2AOBS system (Leica, Wetzlar, Germany) of the Light Microscopy Core Center of the University of Chicago.

In vivo model of intestinal injury. An in vivo model of intestinal stress was performed using a protocol modified from published protocols designed to model NEC $(25,26)$. Rat pups were delivered by cesarean section on the $21 \mathrm{st} \mathrm{d}$ of gestation. Pups were maintained in an incubator at $37^{\circ} \mathrm{C}$ and gavage-fed as described above. Pups were colonized with bacteria $10^{7}$ colony forming units each of Serratia marcescens, Klebsiella pneumoniae, and Streptococci viridans once daily in $100 \mu \mathrm{L}$ formula via the orogastric feeding catheter. In addition, pups were stressed with hypoxia (5\% oxygen and 95\% nitrogen for $10 \mathrm{~min}$ ) three times a day. Pups were killed at indicated time points. Hematoxylin and eosin (H\&E)-stained sections were scored by a blinded pathologist using a validated NEC scoring system with scores ranging from "0" to " 4 " indicating increasing severity of injury (26).

\section{RESULTS}

Mother's milk feeding maintains small intestinal Hsp70 expression. To determine whether the intestine of neonatal rat pups expresses Hsp70, ileal sections of small intestine were analyzed by immunostaining. Hsp70 was present in the epithelial cell compartment to a greater degree in mother's milk-fed pups compared with pups receiving only formula

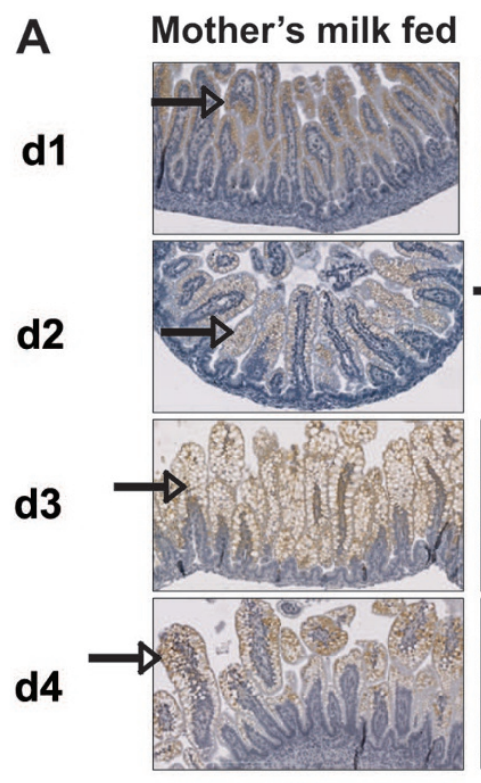

\section{Formula fed}

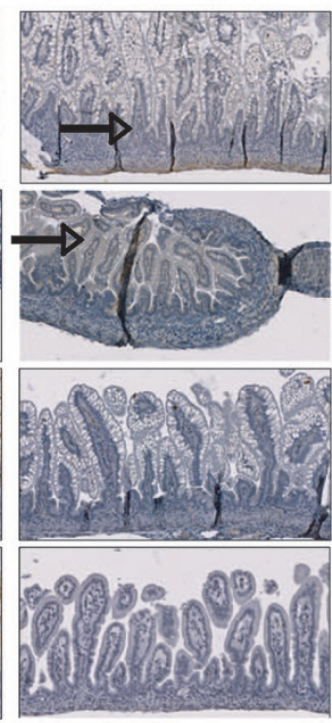

B

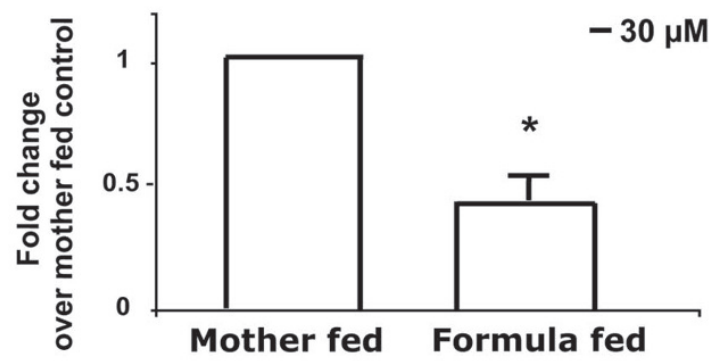

Figure 1. Mother-fed pups maintain small intestinal Hsp70 expression. (A) Rat pups were allowed to suckle (mother's milk-fed) or received only formula (formula-fed) after delivery. Pups were killed at designated days and Hsp70 localized by immunohistochemistry (arrow). Images shown are representative of those of three pups at each day for each condition (magnification $\times 200$ ). (B) Hsp70 mRNA at d 3. Small intestinal tissues were removed at d 3 after birth for both mother's milk- and formula-fed pups. RNA was isolated, reverse transcribed, and Hsp70 and GAPDH analyzed in the cDNA. $\Delta \Delta \mathrm{Ct}$ values were calculated and are shown as fold change compared with mother's milk-fed. Data are means \pm SD for three pups in each group. ${ }^{*} p<0.05$ by paired $t$ test

(Fig. 1A, arrow denotes brown staining indicative of Hsp70 expression). Formula-fed pups demonstrated a time-dependent decrease in Hsp70 staining, whereas the expression of Hsp70 increased in the mother's milk-fed pups.

Rat milk was obtained and analyzed for Hsp70 by ELISA. Hsp70 was found at concentrations of $1.48-2.78 \mathrm{ng} / \mathrm{mL}$ in whole milk $(n=3)$. To determine whether small intestinal Hsp70 expression was additionally due to epithelial expression, mRNA was extracted from extensively washed (three times) tissue from pups at d 3. Hsp70 mRNA was measured and compared by the $\Delta \Delta \mathrm{Ct}$ method. Hsp70 mRNA was readily detected in the washed tissues, demonstrating intestinal epithelial expression. Hsp70 mRNA threshold values were significantly higher for the pups on mother's milk. When $\Delta \Delta \mathrm{Ct}$ value for the pups on mother's milk was set to $1, \mathrm{Hsp} 70$ mRNA values in formula-fed pups were $\sim 50 \%$ lower on $\mathrm{d} 3$ (Fig. 1B), corresponding to the decreased Hsp70 immunostaining shown in Fig. 1. 


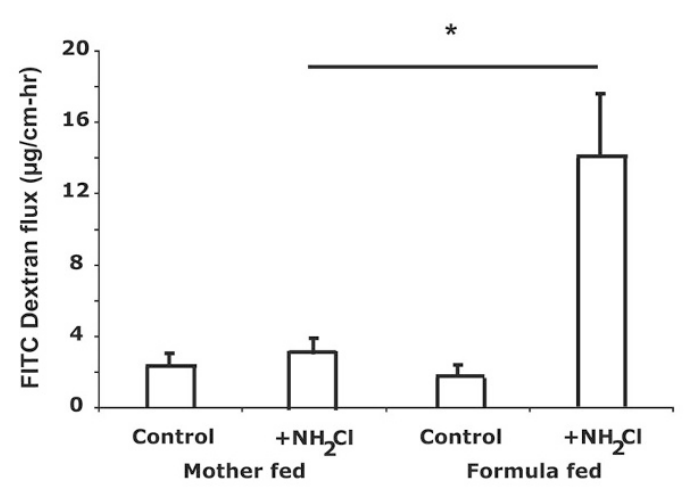

Figure 2. Small intestine of mother's milk-fed pups are resistant to increased permeability by oxidants. Permeability of loops of small intestine of $\mathrm{d} 3$ pups on mother's milk- $v s$ formula-fed was measured using $10 \mathrm{kD}$ FITC-dextran. Loops were treated with monochloramine $\left(\mathrm{NH}_{2} \mathrm{Cl}, 0.1 \mathrm{mM}\right)$ to increase permeability. Data are means \pm SD for three separate pups in each group. ${ }^{*} p<0.05$ by analysis of variance.

Permeability of the small intestine is protected from oxidants in mother's milk-fed pups. Permeability of the small intestine was assessed in ileal loops. The basal permeability was not different between the mother's milk-fed and formulafed ileum (Fig. 2). The oxidant monochloramine $\left(\mathrm{NH}_{2} \mathrm{Cl}\right)$ was used to increase permeability. Loops were filled with a $10-\mathrm{kD}$ fluorescent dextran and movement of this marker to the external bathing medium measured. $\mathrm{NH}_{2} \mathrm{Cl}(0.1 \mathrm{mM})$ did not stimulate increased flux of FITC-dextran in mother's milk-fed pups, demonstrating resistance to oxidant-induced injury. However, the same $\mathrm{NH}_{2} \mathrm{Cl}$ concentration stimulated a large increase in FITC-dextran movement out of the ileal loops of formula-fed pups (Fig. 2).

$\mathrm{ZO}-1$ is a pivotal protein in the maintenance of the tight junction that regulates intestinal permeability. To determine whether Hsp70 was associated with the tight junction, ileal sections were stained for Hsp70 and ZO-1 in mother's milk and formula-fed pups (Fig. 3). Nuclei were visualized using DAPI (blue). In mother's milk fed pups, ZO-1 (green) and Hsp70 (red) colocalized (yellow overlay) at the tight junction. In contrast, formula-fed pups demonstrated little or no Hsp70.

Inflammatory stress does not induce Hsp 70 in formula-fed pups. Adult intestinal epithelial Hsp70 expression may be regulated by many factors including luminal bacteria and immune and inflammatory mediators in the mucosa (16-19). A bacteria exposure/hypoxia injury model was performed on formula-fed pups to determine effect on Hsp70 expression. Pups were killed at varying times after stress and damage scored. As shown in Figure 4, significant damage to the intestinal villi was observed with NEC scores of 2 and 3 as assessed by H\&E images. Hsp70 immunostaining seen in mother's milk-fed animals (arrow, top panel) was not demonstrated in formula-fed pups with or without injury (bottom three panels).

\section{DISCUSSION}

The constant interaction between the intestinal epithelium and the gut microbiota is a challenge for the preterm gut. The mature intestine has many physical barriers designed to limit bacteria to the gut lumen and prevent attachment and translocation across the intestinal epithelium (3). In contrast, several factors make the preterm intestine more susceptible to microbial interaction and translocation (27). Low levels of gastric acid and protective mucus decreased intestinal mobility, and reduced levels of secretory $\operatorname{IgA}$ may contribute to increased bacterial contact (6). In addition, increased intestinal permeability enhances translocation (27). As a counter balance, our data reveal an inducible intestinal protective mechanism that is unique to the immature intestine. In contrast to adults without small intestinal Hsp70 expression, we found that the immature intestine has basal expression of the cytoprotective protein $\mathrm{Hsp} 70$ in the ileum. Increased Hsp70 transcription was

A

\section{Mother's Milk}

B

\section{Formula}

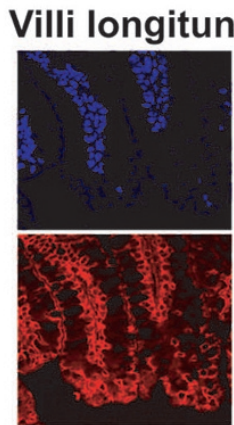

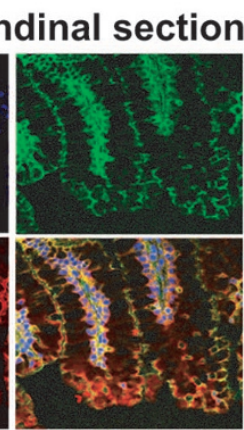

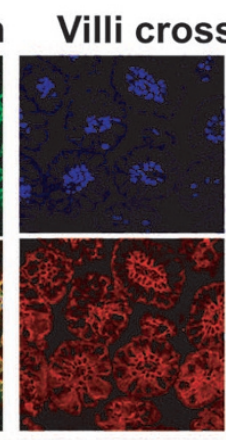

section
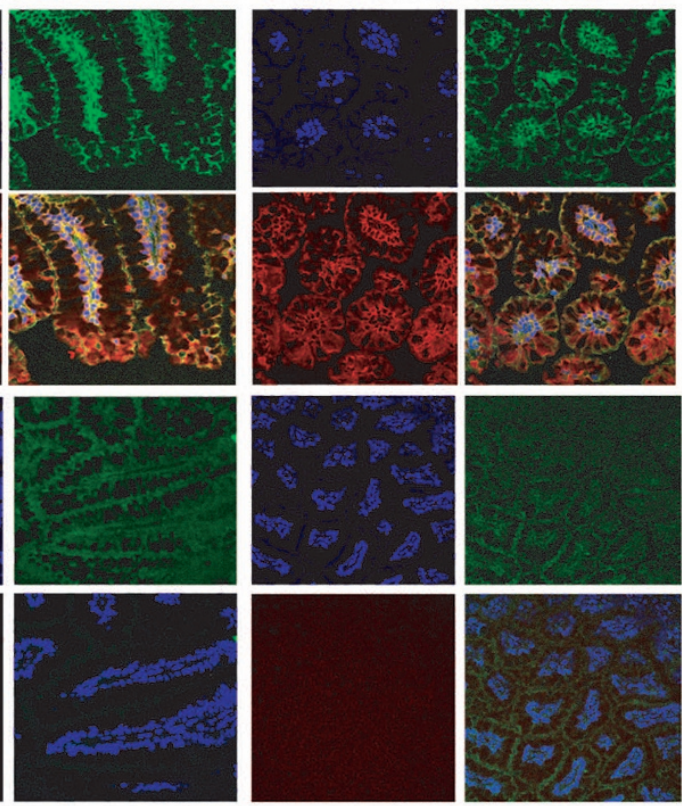
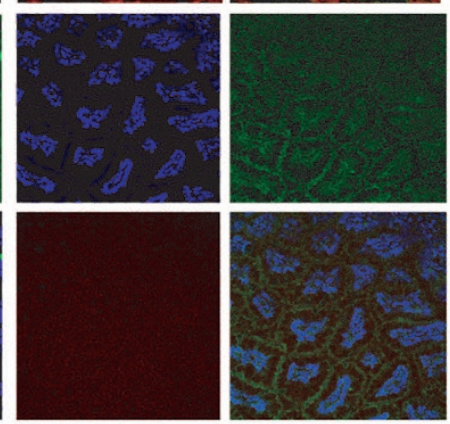

Figure 3. ZO-1 and Hsp70 colocalization in small intestine of mother's milk-fed pups. Frozen sections of small intestine of $(A)$ mother's milk or $(B)$ formula-fed d 3 pups were stained with rabbit polyclonal anti-ZO-1, mouse monoclonal anti-Hsp70, and DAPI to localize nuclei. Images shown are representative of those of three separate pups, two sections were observed for each pup. Blue is nuclear DAPI staining, green for ZO-1, red for Hsp70, and yellow for overlay colocalization (magnification $\times 200$ for formula-fed cross section, all others $\times 400$ ). 


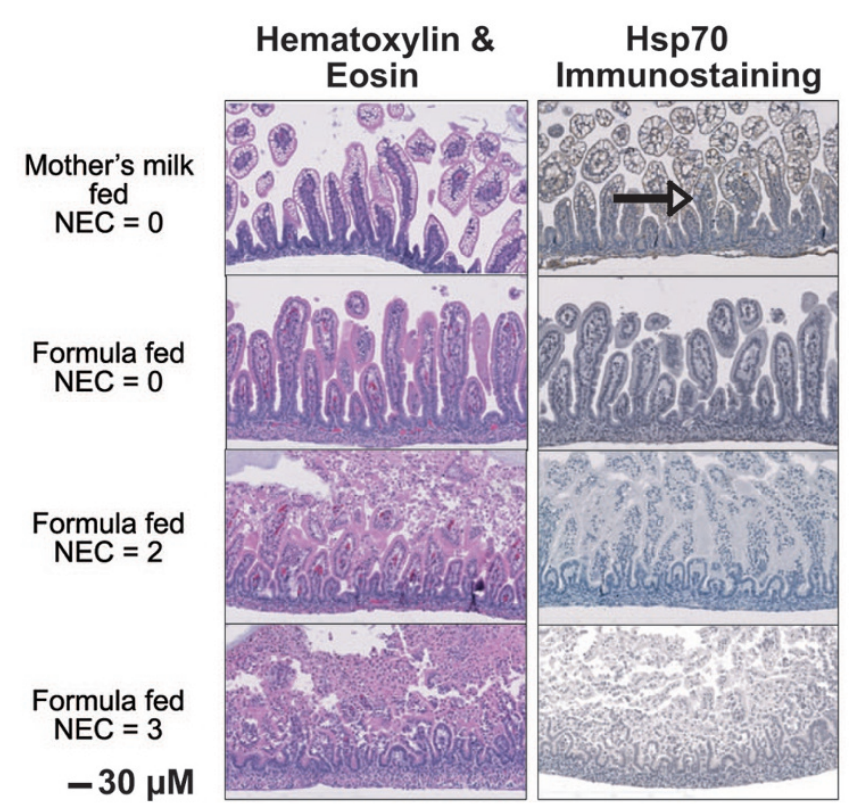

Figure 4. Formula-fed pups demonstrate small intestinal damage but no Hsp70 induction following stress. Formula-fed pups were treated to induce small intestinal inflammation by episodes of hypoxia and bacterial gavage. H\&E-stained small intestinal sections were scored for inflammation. An adjacent section on the same slide was stained for Hsp70 to determine whether the hypoxia/bacteria stress induced Hsp70. Images shown are representative of three separate pups for each group and for each pup, two sections were analyzed (magnification $\times 200$ ).

induced by mother's milk and was noted to colocalize with the tight junction protein $\mathrm{ZO}-1$.

It has been shown in clinical studies, using enteral lactulose/ mannitol administration to evaluate intestinal permeability, that infants receiving formula had increased permeability over the 1 st mo of life compared with infants receiving breast milk (28). Furthermore, clinical studies have documented a decline in the incidence of NEC in human milk-fed infants compared with formula-fed infants, suggesting a protective effect of human milk (29-31). Human milk contains several antibacterial and antiinflammatory factors that may be protective in addition to growth factors that may stimulate intestinal repair through increased cell restitution, growth, and inhibition of apoptosis (32-39). Our findings add to the list of beneficial effects of mother's milk by suggesting that mother's milk contains Hsp70 protein and has factors to promote Hsp70 induction.

Our study does not confirm whether supply of intact Hsp70 present in the milk or induction of Hsp70 in enterocytes is of greater importance. Measurable amounts of secreted Hsp70 were found in expressed mother's milk obtained by gentle suction. It is unknown whether this method of obtaining milk altered milk composition and Hsp70 amounts. Suckling pups also had increased Hsp70 in stained intestinal sections. This is consistent with other studies demonstrating the presence of Hsp70 in bovine milk-producing cells and secreted milk (38). Examination of epithelial RNA demonstrated increased Hsp70 mRNA in ileum from pups fed with mother's milk, suggesting increased transcription. Tissues for mRNA analysis were care- fully washed before analysis to remove any adherent mother's milk and potential contaminating mRNA that may have been secreted into the milk itself.

Hsp70 from mother's milk and epithelial production may both play protective roles; however, our study does not determine the specificity of Hsp70 in preserving barrier function. It is likely that other factors also induced by mother's milk have a role in preservation of the barrier. Future studies examining the effect of mother's milk not containing Hsp70 or exogenous Hsp70 added to formula are necessary to determine the specificity of the role of Hsp70 in intestinal protection. Hsp70 transcription may be stimulated by a mother's milk factor. Lactoferrin, which is known to be found in mother's milk, has been shown to increase Hsp70 in other models and is one potential candidate (40). Additional studies beyond the scope of work are necessary to identify the factors in milk that stimulate Hsp70 production.

Inducible Hsps belong to a family of highly conserved proteins, which play an important role in protecting cells against stressors such as heat, ischemia/reperfusion injury, oxidative stress, or exposure to radiation and toxins $(20,41-$ 44). In the adult rat intestine, induction of Hsps before ischemia-reperfusion preserves mucosal integrity, attenuating mucosal injury and neutrophilic infiltration (45). Hsp70, in particular, protects intestinal epithelial cells against oxidant injury in vitro $(16,20)$. In vivo, commensal bacteria are responsible for inducing the expression of Hsps in the adult intestine $(19,21)$, which likely provide protection against the hostile environment normally found in the gut. Therefore, induction of Hsp70 expression, which results from these bacterial-epithelial cell interactions, plays an important role in maintaining intestinal homeostasis.

Intestinal immaturity of preterm infants increases susceptibility to intestinal injury. NEC is the most common gastrointestinal injury in preterm infants, and human milk has been shown to be protective against this disease. It has been suggested that intestinal barrier disruption may contribute to the pathogenesis of NEC, leading to enhanced translocation of luminal bacteria across the intestinal epithelium, which triggers an inflammatory response resulting in the clinical signs and symptoms of this disease. Several inflammatory mediators including platelet-activating factor, TNF $\alpha$, and IL- $1 \beta$ are known to be elevated in NEC and are able to disrupt the intestinal epithelial barrier. However, it is not known if it is the presence of a harmful mediator or the absence of a protective mediator that increases susceptibility to disease. In our ex vivo model, formula feeding alone did not result in an alteration in barrier function as measured by FITC-dextran translocation in the formula-fed loops. Oxidant injury significantly increased permeability only in loops from formula-fed pups, which did not have Hsp70. Injured intestinal loops from mother's milk-fed pups with abundant epithelial Hsp70 did not have increased permeability. Shoji and Shimizu (39) have previously shown a protective effect of Hsp against oxidant stress in rat jejunal IEC-6 cells. In that study, a specific fraction of human colostrum administered in vitro for $24 \mathrm{~h}$ did not induce Hsp70. Our in vivo model demonstrates that 
whole milk does induce Hsp70 with highest levels beginning at $\mathrm{d} 3$ suggesting that longer exposure or a factor present in whole milk and secreted over time may be necessary. The complex structure of the tight junction suggests that maintenance of appropriate intestinal permeability is multifactorial. The lack of change in baseline permeability suggests that Hsp70 may not be involved in basal regulation of tight junction function. Hsp70 is known to be cytoprotective; thus, it is under conditions of stress that we expect $\mathrm{Hsp} 70$ to play a role. We used $\mathrm{NH}_{2} \mathrm{Cl}$ oxidant-induced stress as a well-described in vitro model of intestinal damage. Our confocal images demonstrate Hsp70 localization to the ZO-1 containing tight junctional region, suggesting that protection may be due to association with ZO-1. However, Hsp70 may also bind other proteins that form the junctional complex.

In adult models, Hsp have been shown to be increased under conditions of stress such as bacteria exposure. We attempted to induce Hsp production in the formula-fed pups without baseline Hsp70 expression by exposure to bacteria and hypoxia in the in vivo model of intestinal injury. These clinically relevant stresses did not increase Hsp70 protein expression, possibly because of induction of inflammation. Other studies have shown that inflammation decreases Hsp70 transcription (17). Our hypothesis is that the Hsp70 needs to be present before inflammatory injury to be protective.

Mother's milk provides many benefits to infants including intestinal protection. Our studies add to the building knowledge base of means by which protection of the intestinal barrier occurs. These results demonstrate that expression of Hsp70 in the neonatal intestine is regulated by exposure to mother's milk. Although Hsp70 is present in mothers milk, additional factors that are absent from formula must be present for the induction of Hsp70 to occur. Further understanding of the means by which mother's milk increases Hsp70 in the ileum will allow potential means of strengthening the intestinal barrier in at-risk preterm infants.

Acknowledgment. We thank Drs. Amy Noffsinger and Maria Westerhoff from the Department of Pathology for their assistance in scoring of the intestinal tissue sections.

\section{REFERENCES}

1. Nusrat A, Turner JR, Madara JL 2000 Molecular physiology and pathophysiology of tight junctions. IV. Regulation of tight junctions by extracellular stimuli: nutrients, cytokines, and immune cells. Am J Physiol Gastrointest Liver Physiol 279:G851G857

2. Mitic LL, Anderson JA 1998 Molecular architecture of tight junctions. Annu Rev Physiol 60:121-142

3. Udall JN, Pang K, Fritze L, Kleinman R, Walker WA 1981 Development of gastrointestinal mucosal barrier. I. The effect of age on intestinal permeability to macromolecules. Pediatr Res 15:241-244

4. Israel EJ 1994 Neonatal necrotizing enterocolitis, a disease of the immature intestinal mucosal barrier. Acta Paediatr Suppl 396:27-32

5. Pácha J 2000 Development of intestinal transport function in mammals. Physiol Rev 80:1633-1667

6. Walker WA 2002 Development of the intestinal mucosal barrier. J Pediatr Gastroenterol Nutr 34:S33-S39

7. Rouwet EV, Heineman E, Buurman WA, ter Riet G, Ramsay G, Blanco CE 2002 Intestinal permeability and carrier-mediated monosaccharide absorption in preterm neonates during the early postnatal period. Pediatr Res 51:64-70

8. Deitch EA 1994 Role of bacterial translocation in necrotizing enterocolitis. Acta Paediatr Suppl 396:33-36
9. Halpern MD, Dominguez JA, Dvorakova K, Houbec H, Williams CS, Meza YG, Ruth MC, Dvorak B 2003 Ileal cytokine dysregulation in experimental necrotizing enterocolitis is reduced by epidermal growth factor. J Pediatr Gastroenterol Nutr 36:126-133

10. Hackam DJ, Upperman JS, Grishin A, Ford HR 2005 Disordered enterocyte signaling and intestinal barrier dysfunction in the pathogenesis of necrotizing enterocolitis. Semin Pediatr Surg 14:49-57

11. Caplan MS, MacKendrick W 1993 Necrotizing enterocolitis: a review of pathogenic mechanisms and implications for prevention. Pediatr Pathol 13:357-369

12. Claud EC, Lu L, Anton PM, Savidge T, Walker WA, Cherayil BJ 2004 Developmentally regulated IkappaB expression in intestinal epithelium ans susceptibility to flagellin-induced inflammation. Proc Natl Acad Sci U S A 101:7404-7408

13. Claud EC, Zhang X, Petrof EO, Sun J 2007 Developmentally regulated tumor necrosis factor alpha induced nuclear factor kappaB activation in intestinal epithelium. Am J Physiol Gastrointest Liver Physiol 292:G1411-G1419

14. Clark JA, Doelle SM, Halpern MD, Saunders TA, Holubec H, Dvorak K, Boitano SA, Dvorak B 2006 Intestinal barrier failure during experimental necrotizing enterocolitis: protective effect of EGF treatment. Am J Physiol Gastrointest Liver Physiol 291:G938-G949

15. Ismail AS, Hooper LV 2005 Epithelial cells and their neighbors. IV. Bacterial contributions to intestinal epithelial barrier integrity. Am J Physiol Gastrointest Liver Physiol 289:G779-G784

16. Musch MW, Kaplan B, Chang EB 2001 Role of increased basal expression of heat shock protein 72 in colonic epithelial c2BBE adenocarcinoma cells. Cell Growth Differ 12:419-426

17. Hu S, Zhu X, Triggs JR, Tao Y, Wang Y, Lichtenstein L, Bissonnette M, Musch MW, Chang EB 2009 Inflammation induced 3'UTR dependent translational inhibition of Hsp70 mRNA impairs intestinal homeostasis. Am J Physiol Gastrointest Liver Physiol 296:G1003-G1011

18. Petrof EO, Ciancio MJ, Chang EB 2004 Role and regulation of intestinal epithelial heat shock proteins in health and disease. Chin J Dig Dis 5:45-50

19. Arvans DL, Vavricka SR, Ren H, Musch MW, Kang L, Rocha FG, Lucioni A, Turner JR, Alverdy J, Chang EB 2005 Luminal bacterial flora determines physiological expression of intestinal epithelial cytoprotective heat shock proteins 25 and 72. Am J Physiol Gastrointest Liver Physiol 288:G696-G704

20. Musch MW, Sugi K, Straus D, Chang EB 1999 Heat-shock protein 72 protects against oxidant-induced injury of barrier function of human colonic epithelial Caco2/bbe cells. Gastroenterology 117:115-122

21. Kojima K, Musch MW, Ren H, Boone DL, Hendrickson BA, Ma A, Chang EB 2003 Enteric flora and lymphocyte-derived cytokines determine expression of heat shock proteins in mouse colonic epithelial cells. Gastroenterology 124:1395-1407

22. Eaves-Pyles T, Wong HR, Alexander JW 2000 Sodium arsenite induces the stress response in the gut and decreases bacterial translocation in a burned mouse model with gut-derived sepsis. Shock 13:314-319

23. David JC, Grongnet JF, Lalles JP 2002 Weaning affects the expression of heat shock proteins in different regions of the gastrointestinal tract of piglets. J Nutr 132:25512561

24. Schmittgen TD, Zakrajsek BA, Mills AG, Gorn V, Singer MJ, Reed MW 2000 Quantitative reverse transcription polymerase chain reaction to study mRNA decay: comparison of end point and real time methods. Anal Biochem 285:194-204

25. Nadler EP, Dickinson E, Knisely A, Zhang X, Boyle P, Beer-Stolz D, Watkins SC, Ford HR 2000 Expression of inducible nitric oxide synthase and interleukin-12 in experimental necrotizing enterocolitis. J Surg Res 92:71-77

26. Jilling T, Simon D, Lu J, Meng FJ, Li D, Schy R, Thomson RB, Soliman A, Arditi M, Caplan MS 2006 The roles of bacteria and TLR4 in rat and murine models of necrotizing enterocolitis. J Immunol 177:3273-3282

27. Go LL, Albanese CT, Watkins SC, Simmons RL, Rowe MI 1994 Breast milk protects the neonate from bacterial translocation. J Pediatr Surg 29:1059-1063

28. Weaver LT, Laker MF, Nelson R 1984 Intestinal permeability in the newborn. Arch Dis Child 59:236-241

29. Pitt J, Barlow B, Heird WC 1977 Protection against experimental necrotizing enterocolitis by maternal milk. I. Role of milk leukocytes. Pediatr Res 11:906-909

30. Dvorak B, Halpern MD, Holubec H, Dovrakova K, Dominquez JA, Williams CS, Meza YG, Kozakova H, McCuskey RS 2003 Maternal milk reduces severity of necrotizing enterocolitis and increases intestinal IL-10 in a neonatal rat model. Pediatr Res 53:426-433

31. Lucas A, Cole TJ 1990 Breast milk and neonatal necrotizing enterocolitis. Lancet 336:1519-1523

32. Chandan RC, Parry RM, Shahani KM 1968 Lysozyme, lipase, and ribonuclease in milk of various species. J Dairy Sci 51:606-607

33. Ronayne de Ferrer PA, Baroni A, Sambucetti ME, López NE, Ceriani Cernadas JM 2000 Lactoferrin levels in term and preterm milk. J Am Coll Nutr 19:370-373

34. Moya FR, Eguchi H, Zhao B, Furukawa M, Sfeir J, Osorio M, Ogawa Y, Johnston JM 1994 Platelet-activating factor acetylhydrolase in term and preterm human milk: a preliminary report. J Pediatr Gastroenterol Nutr 19:236-239

35. Buescher ES, Malinowska I 1996 Soluble receptors and cytokine antagonists in human milk. Pediatr Res 40:839-844

36. Cummins AG, Thompson FM 2002 Effect of breast milk and weaning on epithelial growth of the small intestine in humans. Gut 51:748-754

37. Leaphart CL, Cavallo J, Gribar SC, Cetin S, Li J, Branca MF, Dubowski TD, Sodhi CP, Hackam DJ 2007 A critical role for TLR4 in the pathogenesis of necrotizing enterocolitis by modulating intestinal injury and repair. J Immunol 179:4808-4820 
38. Eitam H, Brosh A, Orlov A, Izhake I, Shabtay A 2009 Caloric stress alters fat characteristics and Hsp70 expression in milk somatic cells of lactating beef cows. Cell Stress Chaperones 14:173-182

39. Shoji H, Shimizu T 2008 Antioxidative properties of human milk and spermine are not related to expression of Hsp70. Acta Paediatr 97:81-84

40. Yokoyama S, Koshio S, Takakura N, Oshida K, Ishikawa M, Gallardo-Cigarroa FJ, Catacutan MR, Teshima S 2006 Effect of dietary bovine lactoferrin on growth response, tolerance to air exposure and low salinity stress conditions in orange spotted grouper Epinephelus coioides. Aquaculture 255:507-513

41. Liu TS, Mark W, Musch MW, Sugi K, Walsh-Reitz MM, Ropeleski MJ, Hendrickson BA, Pothoulakis C, Lamont JT, Chang EB 2003 Protective role of heat shock protein 72 against Clostridium difficile toxin A-induced intestinal epithelial cell dysfunction. Am J Physiol Cell Physiol 284:C1073-C1082
42. Hunt CR, Dix DJ, Sharma GG, Pandita RK, Gupta A, Funk M, Pandita TK 2004 Genomic instability and enhanced radiosensitivity in Hsp70.1 and Hsp70.3-deficient mice. Mol Cell Biol 24:899-911

43. Asano T, Tanaka K, Yamakawa N, Adachi H, Sobue G, Goto H, Takeuchi K, Mizushima T 2009 Hsp70 confers protection against indomethacin-induced lesions of the small intestine. J Pharmacol Exp Ther 330:458-467

44. Matsuda M, Hoshion T, Yamashita Y, Tanaka K, Maji D, Sato K, Adachi H, Sobue G, Ihn H, Funasaka Y, Mizushima T 2010 Prevention of UVB radiation-induced epidermal damage by expression of heat shock protein 70. J Biol Chem 285:5848-5858

45. Töns C, Klosterhalfen B, Klein HM, Rau HM, Anurov M, Oettinger A, Schumpelick V 1997 Induction of heat shock protein 70 (HSP70) by zinc bis (DL-hydrogen aspartate) reduces ischemic small-bowel tissue damage in rats. Langenbecks Arch Chir 382:43-48 